\title{
MENGUKUR EFIKASI PENGAJARAN GURU PELATIH UNIVERSITI SAINS MALAYSIA
}

\section{(MEASURING TEACHING EFFICACY OF STUDENT TEACHERS OF UNIVERSITI SAINS MALAYSIA)}

\author{
Ahmad Zamri Khairani \\ School of Educational Studies, Universiti Sains Malaysia, \\ 11800 USM Pulau Pinang, Malaysia \\ E-mail: ahmadzamri@usm.my
}

Published date: 20 January 2017

To cite this article: Ahmad Zamri Khairani. (2016). Mengukur efikasi pengajaran guru pelatih Universiti Sains Malaysia. Asia Pacific Journal of Educators and Education, 31, 15-25. http://dx.doi.org/10.21315/apjee2016.31.2

To link to this article: http://dx.doi.org/10.21315/apjee2016.31.2

\begin{abstract}
Abstrak: Efikasi pengajaran merupakan variabel penting dalam kajian pendidikan guru kerana pengaruhnya terhadap perkembangan professional guru. Selain daripada itu, efikasi pengajaran turut mempengaruhi variabel-variabel lain lain terutamanya pencapaian murid. Tujuan kajian ini ialah untuk mengukur efikasi pengajaran para guru pelatih di Universiti Sains Malaysia. Seramai 122 orang guru pelatih terlibat sebagai sampel bagi kajian ini. Analisis data yang dikutip melalui instrumen Teachers' Sense of Efficacy Scale menunjukkan para guru pelatih mempunyai efikasi pengajaran yang tinggi. Para guru pelatih menunjukkan keyakinan yang paling tinggi terhadap efikasi dalam pengurusan kelas, diikuti dengan efikasi dalam strategi pengajaran dan efikasi dalam penglibatan dengan murid. Walau bagaimanapun, dalam kajian ini pengkaji membangkitkan beberapa isu yang yang boleh dipertimbangkan, bagi menambah baik program latihan guru sedia ada. Ini termasuklah isu berkaitan kurang keyakinan untuk berhadapan dengan murid yang bermasalah.
\end{abstract}

Kata kunci: efikasi pengajaran, guru pelatih, penglibatan murid, pengurusan kelas, strategi pengajaran, Teachers' Sense of Efficacy Scale

Abstract: Teaching efficacy is considered one of important variable in research related to
teacher education because of its influence in teacher professional development. Besides,
teaching efficacy also influences other variables especially in student achievement. The
purpose of this study is to measure teaching efficacy of student teachers in Universiti
Sains Malaysia. The sample consisted of 122 student teachers. Data analysis collected 
through the Teachers' Sense of Efficacy Scale shows that the student teachers demonstrate high teaching efficacy. They show their highest confidence in classroom management, followed by efficacy in instructional strategies and efficacy in student engagement. However, the researcher raises several issues that can be considered to improve the present teacher training program. This includes lack of confidence to deal with difficult students.

Keywords: teaching efficacy, student teacher, student engagement, classroom management, teaching strategies, Teachers' Sense of Efficacy Scale

\section{PENDAHULUAN}

Program latihan perguruan merupakan satu fasa penting dalam perkembangan professional seorang guru. Dalam fasa ini, para guru pelatih bukan sahaja dilengkapi dengan pengetahuan kandungan mata pelajaran yang diajar, tetapi juga dengan pengetahuan pedagogi. Pengetahuan pedagogi merujuk kepada pengetahuan tentang cara untuk mengajar yang merupakan antara elemen terpenting bagi seseorang guru. Justeru itu, program latihan perguruan biasanya akan memberikan penekanan terhadap kedua-dua aspek pengetahuan ini. Namun begitu, kajian tentang perkembangan professional guru menunjukkan aspek kepercayaan guru juga merupakan elemen penting yang turut mempengaruhi perkembangan profesional mereka (Deemer, 2004). Secara ringkasnya, kepercayaan guru merujuk kepada makna menjadi guru dan juga aspek-aspek yang berkaitan makna tersebut seperti persepsi, keyakinan, sikap, konsepsi, orientasi dan sebagainya (Kagan, 1992; Pajares, 1992). Kepercayaan guru penting kerana ia akan mencorakkan hala tuju pengajaran seseorang guru tersebut. Di samping itu, kajian-kajian menunjukkan kepercayaan guru mempunyai hubungan dengan pelbagai variabel yang dikaitkan dengan profesion perguruan.

Seperti mana yang telah dinyatakan tadi, kepercayaan guru merupakan konsep yang luas. Namun begitu, sorotan kajian dalam pendidikan guru menunjukkan salah satu variabel penting yang menjadi fokus kajian pengkaji-pengkaji ialah efikasi pengajaran. Menurut Bandura (1997), efikasi pengajaran merujuk kepada keyakinan seorang guru terhadap kebolehannya untuk menyelesaikan tugasan bagi menghasilkan keputusan yang dikehendaki. Seorang guru yang mempunyai efikasi pengajaran tinggi berupaya untuk membantu muridnya menghasilkan yang terbaik walaupun dalam keadaan yang sukar. Guru yang mempunyai efikasi pengajaran yang tinggi sentiasa bersikap professional. Sebagai contoh, kajian oleh Labone (2004), Milner (2001) dan juga Wheatley (2005) mendapati guru yang mempunyai efikasi pengajaran yang tinggi sentiasa mahu terlibat secara langsung dengan pengajaran, menunjukkan keupayaan merancang dan mengorganisasi yang tinggi. Selain daripada itu, mereka juga sentiasa berasa puas 
hati dengan profesion tersebut, akan berusaha melakukan tugas-tugas tambahan seperti kelas tuisyen dan sebagainya disamping mempunyai sentiasa bersemangat untuk mengajar. Guru yang mempunyai efikasi pengajaran yang tinggi menunjukkan kecenderungan menggunakan strategi pengajaran berpusatkan murid, manakala guru yang mempunyai efikasi pengajaran rendah lebih berpuas hati dengan strategi berpusatkan guru (Kaufman \& Sawyer, 2004). Kajian oleh Kokkinos (2007) pula menunjukkan guru yang mempunyai efikasi pengajaran yang rendah juga kurang efektif dalam melaksanakan tugas dan tanggungjawabnya. Ciri-ciri yang profesional ini mungkin boleh dikaitkan dengan dapatan bahawa guru yang mempunyai efikasi pengajaran yang tinggi mampu menghasilkan murid yang mempunyai pencapaian yang lebih baik (Guo, Piasta, Justice, \& Kaderavek, 2010; Justice, Mashburn, Hamre, \& Pianta, 2008).

Selain daripada perkembangan professional guru, efikasi pengajaran juga seringkali dikaitkan dengan variabel-variabel lain di dalam domain perkembangan professional guru. Efikasi pengajaran dilaporkan merupakan peramal yang baik bagi komitmen guru (Darling-Hammond, Chung, \& Frelow, 2002; Johnson \& Birkeland, 2003) dan juga kepuasan di tempat kerja (Caprara, Barbaranelli, Steca, \& Malone, 2006). Di samping itu, efikasi pengajaran juga dilaporkan mempunyai hubungan yang negatif dengan tekanan (Klassen \& Chiu, 2010) dan juga fenomena 'burnout' (Schaufeli, \& Salanova, 2007). Sorotan kajian juga menunjukkan banyak aspek yang menjadi peramal (antesedan) kepada efikasi pengajaran. Linn, Gorrell dan Taylor (2002) menyatakan bahawa budaya dan latar belakang pendidikan merupakan elemen penting yang mempengaruhi efikasi pengajaran guru. Menurut Palmer (2006) pula, latihan yang diterima semasa program latihan perguruan memainkan peranan penting dalam pembentukan efikasi pengajaran mereka.

Tujuan kajian ini dijalankan adalah untuk mengukur efikasi pengajaran guru pelatih di Universiti Sains Malaysia. Ia bertujuan untuk menambah pengetahuan berkaitan efikasi pengajaran dalam kalangan guru pelatih bagi mengenalpasti komponen-komponen dalam efikasi pengajaran yang belum dikuasai. Maklumat ini akan digunakan untuk mencadangkan langkah-langkah intervensi bagi menyediakan guru pelatih yang mempunyai keyakinan terhadap kemampuan mereka mengajar. Selain daripada itu, maklumat yang diperolehi dapat dibandingkan dengan dapatan-dapatan daripada kajian lepas bagi membuat justifikasi berkaitan tahap sebenar efikasi pengajaran para guru pelatih Universiti Sains Malaysia. 


\section{SOROTAN KAJIAN}

Walaupun efikasi pengajaran merupakan salah satu tumpuan kajian perkembangan guru, kajian berkaitan dengan sampel guru pelatih di Malaysia adalah terhad. Kebanyakan kajian yang dijalankan bertujuan untuk melihat efikasi pengajaran bagi guru-guru dalam perkhidmatan (Khalid, Zurida, Shuki, \& Ahmad Tajuddin, 2009; Mohd Zaman, Mohd Zuri, Suzana, \& Wan Sharipahmira, 2014). Bagi guru-guru dalam perkhidmatan ini, ramai pengkaji sepakat mengatakan bahawa persekitaran sekolah lebih mempengaruhi efikasi pengajaran guru berbanding dengan faktor-faktor lain seperti faktor individu dan program pendidikan guru (Beard, Hoy, \& Hoy, 2010; Milner \& Hoy, 2003, Deemer, 2004; Demir, 2008). Oleh itu, amat perlu bagi seseorang guru untuk memasuki dunia perguruan dengan efikasi pengajaran tinggi yang dibentuk terutamanya semasa program latihan perguruan mereka. Ini kerana sekiranya guru pelatih tersebut tidak mempunyai efikasi pengajaran yang tinggi, beliau akan menghadapi kesukaran untuk menjalankan tugas dan tanggungjawabnya di sekolah dengan baik. Ini memandangkan terdapat pelbagai jenis cabaran yang perlu dihadapi di sekolah yang tidak didedahkan semasa program pendidikan guru.

Beberapa kajian terhadap efikasi pengajaran guru pelatih boleh diteliti daripada hasil kajian Abdul Rahim, Mohd Majid, Abdul Rashid dan Lyndon (2008), Abdul Rashid, Othman dan Baharom (2013) dan juga Syed Muhammad, Ahmad Zamri, Nordin, Jamalsafri dan Azlinda (2011). Kajian Abdul Rahim et al. (2008) menggunakan 144 orang sampel dari sebuah universiti awam melaporkan para guru pelatih menunjukkan efikasi pengajaran yang tinggi. Mereka paling yakin dengan kebolehan mereka untuk melaksanakan tugas-tugas berkaitan dengan aspek penglibatan murid diikuti dengan strategi pengajaran dan pengurusan kelas. Dapatan yang serupa juga dikongsi oleh kajian Abdul Rashid et al. (2013). Namun begitu, dapatan kajian Syed Muhammad et al. (2011), menunjukkan sampel kajian seramai 442 orang guru pelatih lebih yakin tentang kebolehan mereka dalam aspek strategi pengajaran, diikuti oleh penglibatan murid dan pengurusan kelas. Berdasarkan kajian-kajian ini, masih wujud keperluan untuk mengukur efikasi pengajaran para guru pelatih terutamanya dalam menentukan aspek manakah yang paling kurang dikuasai oleh mereka. 


\section{METODOLOGI}

\section{Sampel}

Sampel kajian terdiri daripada 122 orang guru pelatih tahun dua dan tahun tiga Universiti Sains Malaysia. Sampel terdiri daripada 21 orang guru pelatih lelaki $(17.2 \%)$ dan 101 orang guru pelatih perempuan (82.8\%). Data dikutip daripada sampel yang mengikuti dua kursus yang diajar oleh penyelidik.

\section{Instrumen}

Instrumen yang digunakan bagi tujuan pengumpulan data ialah Teachers' Sense of Eficacy Scale (TSES) yang dibina oleh Tschannen-Moran dan Hoy (2001). Instrumen ini mengandungi 24 item yang mengukur tiga dimensi efikasi pengajaran, iaitu: (1) efikasi dalam pengurusan kelas (8 item), (2) efikasi dalam penglibatan murid (8 item), dan (3) efikasi dalam strategi pengajaran (8 item). Efikasi dalam pengurusan kelas merujuk kepada keyakinan guru tentang kebolehannya untuk memastikan kelas dapat berjalan dengan lancar, manakala efikasi dalam penglibatan murid pula mengukur sejauh manakah guru tersebut percaya beliau boleh menanam sikap yang positif terhadap pengajaran dan pengajaran dalam kalangan murid-muridnya. Item-item bagi efikasi dalam strategi pengajaran pula mengukur keyakinan guru terhadap kebolehannya dalam menggunakan strategi-strategi dan pendekatan pengajaran yang berkesan. TSES dilaporkan mempunyai struktur faktor yang stabil dan kebolehpercayaan yang tinggi yang menjadikannya sesuai untuk mengukur konstruk efikasi pengajaran (Jiening, Youyan, Ji, Gumiko, Guomin, Hitomi, \& Sula, 2015; Klassen, Bong, Usher, Chong, Huan, Wong, \& Georgiou; 2009; Tschannen-Moran \& Hoy, 2001). Instrumen ini juga telah digunakan dengan meluas dalam kajian-kajian di Malaysia (Abdul Rahim et al. 2008; Khalid et al. 2009; Mohd Zaman et al. 2014). Bagi kajian ini, dua pengubahsuaian telah dibuat terhadap TSES. Pertama, instrumen telah diterjemahkan ke dalam bahasa Malaysia, dan kedua, opsyen pada skala Likert telah dikurangkan daripada sembilan poin kepada lima poin. Pengubahsuaian ini dibuat berdasarkan saranan pengkaji seperti Poulou (2007) dan Atay (2007) yang melihat para sampel kajian agak sukar untuk menggunakan skala asal yang mengandungi terlalu banyak poin. Kesukaran yang dilaporkan termasuklah tidak dapat membezakan di antara Sembilan poin yang terlalu dekat. Pengkaji melihat jarak yang lebih jauh di dalam skala lima poin boleh membantu sampel membezakan poin-poin tersebut dengan lebih baik. 


\section{Analisis Data}

Data bagi kajian ini dianalisis dalam dua tahap, iaitu tahap item dan tahap dimensi efikasi pengajaran. Dalam tahap item, frekuensi, peratusan, min dan sisihan piawai digunakan bagi memerihalkan data. Pekali kebolehpercayaan $\alpha$ juga turut dilaporkan bagi menggambarkan konsistensi pengukuran yang dibuat.

\section{DAPATAN DAN PERBINCANGAN KAJIAN}

Kajian ini melaporkan pekali kebolehpercayaan yang tinggi, iaitu $\alpha=.947$ yang bermaksud wujud kemungkinan yang tinggi bahawa pengukuran yang dibuat dalam kajian ini konsisten sekiranya kajian dijalankan menggunakan sampel yang lain. Sepertimana yang ditunjukkan dalam Jadual 1 di bawah, didapati respons para guru pelatih kebanyakannya berada pada skala poin 3 dan poin 4 . Min bagi setiap item berada pada julat 3.60-4.02 yang bermaksud sampel mempunyai keyakinan terhadap kebolehan mereka bagi hampir semua aspek yang ukur. Dapatan ini selari dengan kajian-kajian lepas oleh Fortman dan Pontius (2000) serta Hoy dan Spero (2005). Walau bagaimanapun, statistik sisihan piawai (sp) yang rendah di antara .50-.69 menunjukkan tidak banyak varians yang diukur daripada item-item yang terlibat. Dalam kata lain, item-item dalam TSES kurang mempunyai keupayaan mendiskriminasi di antara guru pelatih yang mempunyai efikasi pengajaran tinggi dan guru pelatih yang mempunyai efikasi pengajaran rendah.

Sampel menunjukkan keyakinan yang paling tinggi dalam Item 5 (Sejauh manakah anda dapat memotivasikan murid lemah? $)(\min =4.02, \mathrm{sp}=.51)$, manakala mereka paling kurang yakin terhadap kebolehan berhadapan murid yang bermasalah (Item 1 : Sejauh manakah anda dapat berhadapan dengan murid yang bermasalah? $)(\min =3.60 . \mathrm{sp}=.64)$. Hal ini agak menarik memandangkan kedua-dua item tersebut mengukur dimensi yang sama iaitu efikasi dalam penglibatan murid dan juga konteks yang sama iaitu murid berpencapaian rendah. Wujud kemungkinan bahawa sampel kajian yakin untuk membantu murid yang lemah dalam subjek yang diajar, tetapi sukar bagi mereka untuk membantu murid yang bermasalah terutamanya bila melibatkan aspekaspek lain yang seringkali dikaitkan dengan murid sekolah seperti masalahmasalah peribadi, keluarga atau rakan sebaya. Ini mungkin disebabkan tiadanya latihan khusus kepada guru pelatih dalam melengkapkan diri mereka dengan kemahiran untuk berhadapan dengan masalah murid semasa dalam latihan perguruan mereka. Namun, seharusnya mereka sedar bahawa tugas dan tanggungjawab guru di sekolah bukanlah terhad kepada pengajaran sahaja tetapi 
juga turut merangkumi tugas dan tanggungjawab yang melibatkan murid dan juga pentadbiran.

Jadual 1. Frekuensi, Peratusan, Min dan Sisihan Piawai Item TSES

\begin{tabular}{ccccccccccccc}
\hline Item & 1 & $\%$ & 2 & $\%$ & 3 & $\%$ & 4 & $\%$ & 5 & $\%$ & Min & sp \\
\hline 1 & 0 & 0 & 3 & 2.5 & 50 & 41.0 & 62 & 50.8 & 7 & 5.7 & 3.60 & .64 \\
2 & 0 & 0 & 1 & 0.8 & 44 & 36.1 & 73 & 59.8 & 4 & 3.3 & 3.66 & .56 \\
3 & 0 & 0 & 0 & 0.0 & 40 & 32.8 & 71 & 58.2 & 11 & 9.0 & 3.76 & .60 \\
4 & 0 & 0 & 0 & 0.0 & 21 & 17.2 & 87 & 71.3 & 14 & 11.5 & 3.94 & .54 \\
5 & 0 & 0 & 0 & 0.0 & 14 & 11.5 & 91 & 74.6 & 17 & 13.9 & 4.02 & .51 \\
6 & 0 & 0 & 0 & 0.0 & 16 & 13.1 & 92 & 75.4 & 14 & 11.5 & 3.98 & .50 \\
7 & 0 & 0 & 1 & 0.8 & 44 & 36.1 & 71 & 58.2 & 6 & 4.9 & 3.67 & .58 \\
8 & 0 & 0 & 1 & 0.8 & 29 & 23.8 & 80 & 65.6 & 12 & 9.8 & 3.84 & .59 \\
9 & 0 & 0 & 3 & 2.5 & 30 & 24.6 & 71 & 58.2 & 18 & 14.8 & 3.85 & .69 \\
10 & 0 & 0 & 2 & 1.6 & 22 & 18.0 & 80 & 65.6 & 18 & 14.8 & 3.93 & .63 \\
11 & 0 & 0 & 1 & 0.8 & 23 & 18.9 & 89 & 73.0 & 9 & 7.4 & 3.87 & .53 \\
12 & 0 & 0 & 1 & 0.8 & 33 & 27.0 & 73 & 59.8 & 15 & 12.3 & 3.84 & .64 \\
13 & 0 & 0 & 0 & 0.0 & 32 & 26.2 & 77 & 63.1 & 13 & 10.7 & 3.84 & .59 \\
14 & 0 & 0 & 0 & 0.0 & 17 & 13.9 & 95 & 77.9 & 10 & 8.2 & 3.94 & .47 \\
15 & 0 & 0 & 2 & 1.6 & 36 & 29.5 & 71 & 58.2 & 13 & 10.7 & 3.78 & .65 \\
16 & 0 & 0 & 0 & 0.0 & 31 & 25.4 & 80 & 65.6 & 11 & 9.0 & 3.84 & .57 \\
17 & 0 & 0 & 0 & 0.0 & 33 & 27.0 & 78 & 63.9 & 11 & 9.0 & 3.82 & .58 \\
18 & 0 & 0 & 1 & 0.8 & 30 & 24.6 & 80 & 65.6 & 11 & 9.0 & 3.83 & .59 \\
19 & 0 & 0 & 0 & 0.0 & 47 & 38.5 & 67 & 54.9 & 8 & 6.6 & 3.68 & .59 \\
20 & 0 & 0 & 0 & 0.0 & 26 & 21.3 & 86 & 70.5 & 10 & 8.2 & 3.87 & .53 \\
21 & 0 & 0 & 0 & 0.0 & 58 & 47.5 & 52 & 42.6 & 12 & 9.8 & 3.62 & .66 \\
22 & 0 & 0 & 2 & 1.6 & 35 & 28.7 & 72 & 59.0 & 13 & 10.7 & 3.79 & .65 \\
23 & 0 & 0 & 0 & 0.0 & 20 & 16.4 & 86 & 70.5 & 16 & 13.1 & 3.97 & .54 \\
24 & 0 & 0 & 0 & 0.0 & 30 & 24.6 & 81 & 66.4 & 11 & 9.0 & 3.84 & .56 \\
\hline Petunjuk: & $1=$ Tiada apa yang boleh dilakukan dilakukan & & & & \\
& & $2=$ & Sangat sedikit sahaja yang dapat dilakukan & & & & \\
& & $4=$ & Agak banyak yang boleh dilakukan & & & & & \\
& & $5=$ & Banyak yang boleh dilakukan & & & & & & \\
\hline
\end{tabular}

Pada tahap dimensi efikasi pengajaran, para guru pelatih menunjukkan keyakinan yang paling tinggi terhadap efkasi dalam pengurusan kelas $(\min =31.97$, $\mathrm{sp}=3.81)$ diikuti dengan efikasi dalam strategi pengajaran $(\min =31.24$, $\mathrm{sp}=3.16)$ dan efikasi dalam penglibatan dengan murid $(\min =31.03, \mathrm{sp}=3.23)$. 
Para guru pelatih mengatakan bahawa mereka mempunyai lebih keyakinan terhadap kebolehan mereka dalam aspek pengurusan kelas seperti mengawal peraturan, mengawal tingkahlaku murid, menenangkan murid yamg membuat bising dan menangani murid yang tidak mendengar kata. Namun begitu, sesuatu yang menarik untuk dibandingkan ialah efikasi dalam pengurusan kelas sentiasa menjadi aspek yang kurang diyakini oleh kumpulan guru yang pernah terlibat secara langsung di dalam kelas. Sebagai contoh, kajian oleh Syed Muhammad et al. (2011) terhadap guru pelatih yang telah menjalani latihan mengajar yang mengatakan mereka paling kurang yakin terhadap aspek pengurusan kelas. Kajian menggunakan sampel guru dalam perkhidmatan oleh Abdul Rahim dan Shamsiah (2013) juga menunjukkan dapatan yang sama, manakala kajian oleh Rahimah, Rosini, Abdullah dan Habsah (2012) serta Khalid et al. (2009) menunjukkan pengurusan kelas bukanlah aspek yang mudah bagi para guru dalam perkhidmatan. Berdasarkan senario persekolahan pada hari ini, umum berpendapatan bahawa pengurusan kelas merupakan aspek yang mencabar. Justeru itu apa yang dibimbangkan ialah para guru pelatih mempunyai persepsi yang salah terhadap aspek ini. Ada kemungkinan para guru pelatih masih beranggapan situasi pengajaran dan pembelajaran adalah seperti mana semasa mereka berada di sekolah dahulu, dan bukannya pada masa sekarang seperti mana yang dilaporkan Alger (2009). Ini tentunya akan mendatangkan masalah apabila mereka berhadapan dengan realiti sebenar di sekolah yang mungkin akan menyebabkan gangguan kepada perkembangan professional mereka sendiri (Kim \& Cho, 2014). Dalam hal ini, program latihan perguruan dilihat sebagai platform terbaik untuk membentuk kepercayaan guru yang lebih relistik terhadap profesion perguruan (Barcelos, 2003).

\section{PENUTUP}

Tujuan kajian ini dijalankan ialah untuk mengukur efikasi pengajaran guru-guru pelatih Universiti Sains Malaysia. Dalam kajian yang dijalankan juga, pengkaji telah mendapatkan bukti bahawa iunstrumen TSES yang digunakan menunjukkan bukti kebolehpercayaan dan kesahan yang baik. Justeru itu, instrumen ini sesuai digunakan untuk mengukur efikasi pengajaran guru. Dapatan menunjukkan bahawa para guru pelatih dalam kajian ini menunjukkan efikasi pengajaran yang tinggi, manakala min skor item memberikan makluman berkaitan keyakinan para guru pelatih tentang aspek-aspek pengurusan kelas, penglibatan murid dan juga strategi pengajaran. Maklumat-maklumat ini boleh dijadikan panduan terutamanya dalam menambahbaik program latihan perguruan di Universiti Sains Malaysia. Namun begitu, kajian ini juga membangkitkan persoalan berkaitan tanggapan para guru pelatih berkaitan kebolehan mereka mengajar yang tidak selari dengan realiti profesion perguruan pada masa ini. Hal ini perlu diberi 
perhatian lanjut agar ketidakselarasan ini dapat difahami terutamanya oleh guru pelatih itu sendiri sebelum mereka memasuki dunia perguruan.

\section{RUJUKAN}

Abdul Rahim Bakar, \& Shamsiah Mohamed (2013). Teacher efficacy beliefs among novice Malaysian teachers. The International Journal of Learning, 16(5), 497510.

Abdul Rahim Bakar, Mohd Majid Konting, Abdul Rashid Jamian, \& Lyndon, N. (2008). Teaching efficacy of Universiti Putra Malaysia science student teachers. College Student Journal, 42, 493-509.

Abdul Rashid Jamian, Othman, S., \& Baharom, R. (2013). The teaching efficacy among trainee teachers in the classroom environment. ICERI2013 proceedings, 36143619.

Alger, C. L. (2009). Secondary teachers' conceptual metaphors of teaching and learning: Changes over the career span. Teaching and Teacher Education, 25, 743-751. http://dx.doi.org/10.1016/j.tate.2008.10.004

Atay, D. (2007). Beginning teacher efficacy and the practicum in EFL context. Teacher Developement, 11, 203-219. http://dx.doi.org/10.1080/13664530701414720

Bandura, A. (1997). Self-efficacy: The exercise of control. New York: W. H. Freeman.

Barcelos, A. M. F. (2003). Researching belief about SLA: A critical review. In P. Kalaja \& A. M. F. Barcelos (Eds.). Belief about SLA: New Resarch Approaches (pp. 7 33). Dordrech : Kluwer Academic Publishers. http://dx.doi.org/10.1007/978-14020-4751-0_1

Beard, K. S., Hoy, W. K., \& Hoy, A. W. (2010). Academic optimism of individual teachers: Confirming a new construct. Teaching and Teacher Education, 26(5), 1136-1144. http://dx.doi.org/10.1016/j.tate.2010.02.003

Caprara, G. V., Barbaranelli, C., Steca, P., \& Malone, P. S. (2006). Teachers' selfefficacy beliefs as determinants of job satisfaction and students' academic achievement: A study at the school level. Journal of School Psychology, 44, 473-490. http://dx.doi.org/10.1016/j.jsp.2006.09.001

Darling-Hammond, L., Chung, R., \& Frelow, F. (2002). Variation in teacher preparation: How well do different pathways prepare teachers to teach? Journal of Teacher Education, 53, 286-302. http://dx.doi.org/10.1177/0022487102053004002

Deemer, S. (2004). Classroom goal orientation in high school classrooms: Revealing links between teacher beliefs and classroom environments. Educational Research, 46(1), 73-90. http://dx.doi.org/10.1080/0013188042000178836

Demir, K. (2008). Transformational leadership and collective efficacy: The moderating roles of collaborative culture and teachers' self-efficacy. Eurasian Journal of Educational Research, 8(33), 93-112.

Fortman, C. K., \& Pontius, R. (2000). Self-efficacy during student teaching. Paper presented at the annual meeting of the Mid-Western Educational Research Association, Chicago, IL. 
Guo, Y., Piasta, S.B., Justice, L. M. \& Kaderavek, J. N. (2010). Relations among preschool teachers' self-efficacy, classroom quality, and children's language and literacy gains. Teaching and Teacher Education, 26, 1094-1103. http://dx.doi.org/10.1016/j.tate.2009.11.005

Hoy, A., \& Spero, R.B. (2005). Changes in teacher-efficacy during the early years of teaching: A comparison of four measures. Teaching and Teacher Education, 21(4), 343-356. http://dx.doi.org/10.1016/j.tate.2005.01.007

Jiening, R., Youyan, N., Ji, H., Gumiko, M., Guomin. Z, Hitomi, K., \& Sula, Y. (2015). Cross-cultural validation of Teachers' Sense of Efficacy Scale in three Asian countries: Test of measurement invariance. Journal of Psychoeducational Assessment, 1-11.

Johnson, S. M. \& Birkeland, S. E. (2003). Pursuing a "sense of success": New teachers explain their carrer decisions. American Education Research Journal, 40(3), 582-617. http://dx.doi.org/10.3102/00028312040003581

Justice, L.M., Mashburn, A., Hamre, B., \& Pianta, R. (2008). Quality of language and literacy instruction in preschool classrooms serving at-risk pupils. Early Childhood Research Quarterly, 23, 51-68. http://dx.doi.org/10.1016/j.ecresq. 2007.09.004

Kagan, D. M. (1992). Implications of research on teacher belief. Educational Psychologist, 27(1), 65-90. http://dx.doi.org/10.1207/s15326985ep2701_6

Kaufman, S. E. R. \& Sawyer, B. E. (2004). Primary-grade teachers' self-efficacy, beliefs, attitudes towards teaching, and discipline and teaching practice priorities in relation to the responsive classroom approach. The Elementary School Journal, 104(4), 321-341.

Khalid Johari, Zurida Ismail, Shuki Osman, \& Ahmad Tajuddin Othman (2009). Pengaruh jenis latihan guru dan pengalaman mengajar terhadap efikasi guru sekolah menengah. Jurnal Pendidikan Malaysia, 34(2), 3-14.

Kim, H., \& Cho, Y. (2014). Preservice teachers' motivation, teaching efficacy, and expectation of reality shock. Asia-pacific Journal of Teacher Education, 42(1), 67-81. http://dx.doi.org/10.1080/1359866X.2013.855999

Klassen, R. M.,\& Chiu, M. M. (2010). Effects on teachers' self-efficacy and job satisfaction: Teachers gender, years of experience, and job stress. Journal of Educational Psychology, 102(3), 741-756. http://dx.doi.org/10.1037/a0019237

Klassen, R. M., Bong, M., Usher, E. L., Chong, W. H., Huan, V. S., Wong, I. Y. F., \& Georgiou, T. (2009). Exploring the validity of a teachers' self-efficacy scale in five countries. Contemporary Educational Psychology, 34(1), 67-76. http://dx.doi.org/10.1016/j.cedpsych.2008.08.001

Kokkinos, C. M. (2007). Job stressors, personality, and burnout in primary school teachers. British Journal of Educational Psychology, 77, 229-243. http://dx.doi.org/10.1348/000709905X90344

Labone, E. (2004). Teacher efficacy: Maturing the construct through research in alternative paradigms. Teaching and Teacher Education, 20, 341-359. http://dx.doi.org/10.1016/j.tate.2004.02.013

Linn, H., Gorrell, J. \& Taylor, J. (2002). Influence of culture and education on U.S. and Taiwan preservice teachers' efficacy beliefs. The Journal of Educational Research, 96(1), 37-46. http://dx.doi.org/10.1080/00220670209598789 
Masitah Mohammad Yusof, Azizi Muda, Ahmad Makmom Abdullah, Bahaman Abu Samah, Ramli Basri, \& Noriati A. Rashid (2013). Faktor-faktor yang mempengaruhi efikasi kendiri guru sekolah menengah di Malaysia dalam pelaksanaan pendidikan alam sekitar. Asia Pacific Journal of Educators and Education, 28, 131-153.

Milner, H. R., \& Hoy, H. W. (2003). A case study of an African American teacher's selfefficacy, stereotype threat, and persistence. Teaching and Teacher Education,19(2), 263-276. http://dx.doi.org/10.1016/S0742-051X(02)00099-9

Mohd Zaman Hashim, Mohd Zuri Abdul Ghani, Suzana Ibrahim, \& Wan Sharipahmira Zain (2014). The relationship between teachers' self-efficacy and attitudes towards inclusive education in Pulau Pinang. International Journal of Research in Social Sciences, 4(7), 24-33.

Nurahimah Mohd Yusoff, \& Rafisah Osman (2010). Hubungan kualiti penyeliaan pengajaran dan pembelajaran di bilik darjah dengan efikasi guru. Asia Pacific Journal of Educators and Education, 25, 53-71.

Pajares, M. F. (1992). Teachers' beliefs and educational research: Cleaning up a messy construct. Review of Educational Research, 62(3), 307-333. http://dx.doi.org/ $10.3102 / 00346543062003307$

Palmer, D. H. (2006). Sources of self-efficacy in a science methods course for primary teacher education students. Research in Science Education, 36, 337-353. http://dx.doi.org/10.1007/s11165-005-9007-0

Poulou, M., 2007. Personal teaching efficacy and its sources: Student teachers' perceptions. Eductional Psychology, 27, 191-218. http://dx.doi.org/10.1080/ 01443410601066693

Rahimah Jamaluddin, Rosini Abu, Abdullah Mat Rashid, \& Habsah Ismail (2012). Tahap efikasi kendiri guru dalam melaksanakan pengajaran kekeluargaan. Paper presented at Seminar Majlis Dekan-dekan Pendidikan IPTA. Retrieved 21 April 2015 from http://www.fp.utm.my/ePusatSumber/listseminar/medc2012/ pdf/103.pdf

Schaufeli, W. B., \& Salanova, M. (2007). Efficacy or inefficacy, that's the question: Burnout and work engagement, and their relationships with efficacy beliefs. Anxiety, Stress, \& Coping: An International Journal, 20(2), 177-196. http://dx.doi.org/10.1080/10615800701217878

Syed Muhammad Syed Abdullah, Ahmad Zamri Khairani, Nordin Abd. Razak, Jamalsafri Saibon, \& Azlinda Mohd Ariff (2011). Teaching efficacy among college student-teachers of diverse background. World Applied Sciences Journal, 14 (Learning Innovation and Intervention for Diverse Learners), 28-33.

Tschannen-Moran, M., \& Hoy, W. A. (2001). Teacher efficacy: Capturing an elusive construct. Teaching and Teacher Education, 17, 783-805. http://dx.doi.org/ 10.1016/S0742-051X(01)00036-1

Wheatley, K. F. (2005). The case for reconceptualizing teacher efficacy research. Teaching and Teacher Education, 21, 747-766. http://dx.doi.org/10.1016/ j.tate.2005.05.009 